Webley, D. M., Duff, R. B. \& Farmer, V. C. (1955). J. gen. Microbiol. 13, 361-369

\title{
Beta-oxidation of Fatty Acids by Nocardia opaca
}

\author{
By D. M. WEBLEY, R. B. DUFF AND V. C. FARMER \\ The Macaulay Institute for Soil Research, Craigiebuckler, Aberdeen
}

\begin{abstract}
SUMMARY: A study of the mechanism of breakdown of $\omega$-phenyl-substituted fatty acids by Nocardia opaca has been made. Acids with an odd number of carbon atoms in the side chain (phenylpropionic, phenylvaleric and phenylheptylic acids) were converted to benzoic acid, and cinnamic acid was an intermediate. o-Hydroxyphenylacetic acid was identified as a common product when acids with an even number of carbon atoms (phenylacetic, phenylbutyric, phenylcaproic and phenylcaprylic) were used. This evidence supports $\beta$-oxidation as a mechanism of breakdown of short chain fatty acids by $N$. opaca.
\end{abstract}

It was shown that Nocardia opaca would grow on a wide range of saturated aliphatic fatty acids as sole carbon and energy source (Webley, 1954), and that washed suspensions of glucose grown cells gave enhanced oxygen uptake in the presence of these acids (Webley \& DeKock, 1952). The mechanism by which acid-fast organisms attack fatty acids is, at present, unknown. In the present work the metabolism of $\omega$-phenyl-substituted fatty acids by $N$. opaca has been studied and the results are in favour of $\beta$-oxidation of the short chain fatty acids by this organism. Growth experiments, manometric measurements, spectrochemistry and chromatography have been employed.

\section{METHODS}

Organism. Nocardia opaca, strain $\mathrm{T}_{16}$ was used throughout (Webley \& DeKock, 1952).

Growth experiments. These were carried out as previously described (Webley, 1954), but with substrates at $0.01 \mathrm{~m}$ concentration, unless otherwise stated.

Production of cells for oxygen uptake measurements, etc. Organisms were grown on liquid medium as previously (Webley \& DeKock, 1952), but the shaking machine of Webley \& Duff (1955) was used. Medium containing $2 \%(\mathrm{w} / \mathrm{v})$ glucose was used in $200 \mathrm{ml}$. lots in 1 1. Pyrex culture flasks (Jobling Cat. No. 1410). Incubation was at $25^{\circ}$ for $4-6$ days.

Manometric experiments. Measurements of $\mathrm{O}_{2}$ uptake were carried out as before (Webley \& DeKock, 1952), substrates being tipped in from the side arm of the Warburg flasks after the overnight incubation required to decrease endogenous activity. For adaptation experiments the 'exposure' technique of Silliker \& Rittenberg (1951) was used. For this purpose phenyl-substituted fatty acids $(0 \cdot 4 \mu \mathrm{mole} / \mathrm{ml}$.) were added to the suspensions of the glucose-grown cells at the beginning of the overnight incubation period. Before substrates were tipped in next morning readings were taken for $30 \mathrm{~min}$. to ensure that the 
endogenous respiration in each vessel was the same. The rate rarely varied more than $10 \%$ from one vessel to the next. Readings were taken at $10 \mathrm{~min}$. intervals after addition of the substrates.

Larger scale experiments for detection of intermediates. These were performed on the shaking machine used for the production of the cells. The same type of flask was employed containing $100 \mathrm{ml}$. of 0.0133 m-phosphate $(\mathrm{pH} 7 \cdot 2)$, 5-25 $\mu \mathrm{mole} / \mathrm{ml}$. phenyl substituted acid (as sodium salt) and 200-400 mg. (dry weight) of washed glucose-grown cells. Strict aseptic conditions were observed as the experiments were sometimes continued over a number of days. Samples were withdrawn periodically when required, centrifuged and examined spectrochemically as described below. Chromatographic analyses were performed when desirable during the course or at the end of the experiment when the whole contents of the flasks were used.

Spectrochemical techniques. The ultraviolet absorption spectra of samples taken from the large-scale experiments were determined in both acid and alkaline solution. Absorption measurements were made at $5 \mathrm{~m} \mu$. intervals between 200 and $350 \mathrm{~m} \mu$. using a Beckman model D.U. spectrophotometer. The estimation of benzoic and cinnamic acids in the presence of $\omega$-phenyl substituted fatty acids depends on the intense absorption maxima of benzoic acid at $229 \mathrm{~m} \mu \cdot\left(\epsilon=1 \cdot 10 \times 10^{4}\right)$ and of cinnamic acid at $278 \mathrm{~m} \mu \cdot\left(\epsilon=2 \cdot 04 \times 10^{4}\right)$. At these wavelengths the phenyl substituted fatty acids show only weak absorption. The estimation of phenols formed from the substituted fatty acids depends on the rise in absorption which occurs with simple phenols on passing from acid to alkaline solution. For this purpose absorption measurements at 290 and $240 \mathrm{~m} \mu$. were made in acid and alkaline solution. $o$-Hydroxyphenylacetic acid was used as a standard.

Paper chromatography. Unidimensional paper chromatography was carried out by the descending technique with stainless steel troughs enclosed in bell jars accommodated in a chamber thermostatically controlled at $23^{\circ}$. Organic acids were identified by the method of Fewster \& Hall (1951) with ammonia + ammonium carbonate buffered $n$-butanol as developing solvent and a buffered solution of bromophenol blue and methyl red as a spray. Cnsaturated acids were detected as white spots on a light reddish purple background when the chromatogram was sprayed with a dilute aqueous solution $(0 \cdot 1-0.5 \%, \mathrm{w} / \mathrm{v})$ of potassium permanganate. Phenols and phenolic acids were detected by the diazotized sulphanilic acid spray of Evans, Parr \& Evans (1949). The developer of Fewster \& Hall (1951) gave good separations with these compounds, and was rather more convenient than the butanol + pyridine + saturated $\mathrm{NaCl}$ solution used by Evans et al. (1949).

In general, cells from large-scale experiments were separated by centrifuging, and the acidified $(\mathrm{HCl})$ supernatant solution was extracted six times with small amounts of ether in a separating funnel. The ether was removed and the residue dissolved in a few drops of acetone and applied to the origin of the chromatogram. Normally a standard substance was applied to each side of the paper and the unknown material spotted in the centre. A very small difference in $\boldsymbol{R}_{\boldsymbol{F}}$ value could be detected in this way. 


\section{RESULTS \\ Experiments with benzoic acid and odd numbered phenyl- substituted fatty acids}

Nocardia opaca did not grow with benzoic acid as carbon source. Similarly, very little growth was obtained on phenylpropionic ( $\mathrm{PhC}-3)$ phenylvaleric (PhC-5) and phenylheptylic (PhC-7) acids (Table 4). However, washed cell suspensions of $N$. opaca showed no increased oxygen uptake in the presence of benzoic acid but gave marked increases with the other compounds (Table 1).

Table 1. The oxygen uptake of Nocardia opaca in the presence of benzoic, cinnamic, phenylpropionic, phenylvaleric and phenylheptylic acids

Each vessel contained $5.7 \mathrm{mg}$. dry weight of a washed suspension of glucose-grown cells of $N$. opaca, $0.5 \mathrm{ml} .0 .066 \mathrm{M}$-phosphate $(\mathrm{pH} 7 \cdot 2)$ and distilled water to give $2.0 \mathrm{ml}$. After overnight incubation $0.5 \mathrm{ml}$. of distilled water or $0.01 \mathrm{M}$-sodium salts of the acids were tipped in from the side arm.

\begin{tabular}{lc}
\multicolumn{1}{c}{ Addition } & $\mathrm{O}_{2}$ uptake in $\mathbf{1 8 0} \mathrm{min}$. \\
None & $(\mu \mathrm{l})$. \\
Benzoate & 121 \\
Cinnamate & 129 \\
Phenylpropionate & 198 \\
Phenylvalerate & 187 \\
Phenylheptylate & 237 \\
& 379
\end{tabular}

The manometric experiments suggested the possibility that the side chain of $\mathrm{PhC}-3, \mathrm{PhC}-5, \mathrm{PhC}-7$ was oxidized to benzoic acid as would be expected for $\beta$-oxidation. The following experiments showed that this occurred, and that cinnamic acid was produced as an intermediate in the breakdown of these acids to benzoic acid.

The production of cinnamic and benzoic acids from phenylpropionic, phenylvaleric and phenylheptylic acids by washed cells of Nocardia opaca

A culture flask containing $100 \mathrm{mI} .0 \cdot 0133 \mathrm{M}$-phosphate $(\mathrm{pH} \tau \cdot 2), 25 \mu$ mole $/ \mathrm{ml}$. phenylpropionate and $372 \mathrm{mg}$. (dry weight) of glucose-grown cells was set up as described under Methods. Samples were periodically removed, with aseptic precautions, centrifuged and examined spectrochemically. After incubation for $48 \mathrm{hr}$. the maxima due to benzoic and cinnamic acids are distinct and the sum of the absorptions of the three constituent acids yield the observed $48 \mathrm{hr}$. spectrum at every wavelength between 210 and $330 \mathrm{~m} \mu$. (Fig. 1). Excellent agreement between the observed and the calculated spectrum was also found for alkaline solutions. As the spectra of both benzoic and cinnamic acids change on going from acid to alkaline solution this gives independent confirmation of the presence of these acids. Successive absorptiometric analyses of the phenylpropionic acid solution at intervals over the complete experiment shows that the benzoic acid concentration rises steadily until the substrate is exhausted, and the conversion is approximately quantitative; the concentration of cinnamic acid rises to a maximum and then falls to zero at the end of 
the experiment (Fig. 2). It is clear, therefore, that cinnamic acid is an intermediate in the oxidation of phenylpropionic acid to benzoic acid by Nocardia opaca. Moreover, authentic cinnamic acid ( $2 \mu \mathrm{mole} / \mathrm{ml}$.) was oxidized to benzoic acid by $N$. opaca.

The formation of benzoic acid from phenylpropionic acid was finally confirmed by its isolation at the end of the experiment. The cells were removed by centrifuging and the supernatant was acidified and extracted with ether. The ether extract yielded crystalline benzoic acid, which was purified by sublimation and identified by its infra-red spectrum.

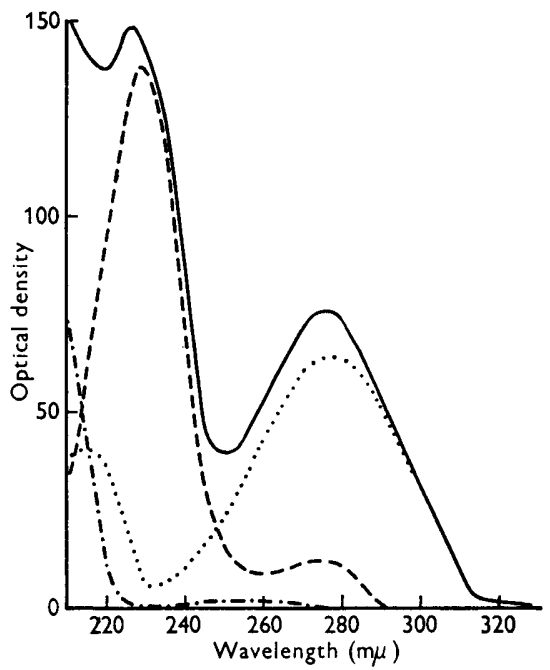

Fig. 1

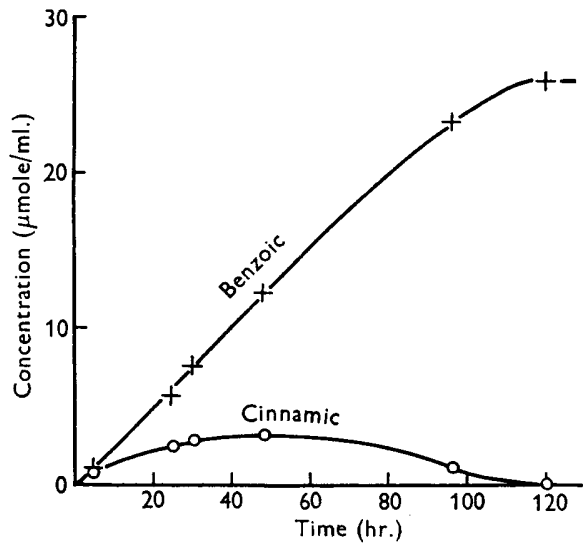

Fig. 2

Fig. 1. Absorption spectrum of a solution, originally containing $25 \mu \mathrm{mole} / \mathrm{ml}$. phenylpropionic acid, after $48 \mathrm{hr}$. incubation with Nocardia opaca (-). For comparison, the spectra of the separate constituents of the above solution are given as follows: benzoic acid (- - - ), cinnamic acid ( .....), and residual phenylpropionic acid (-.......).

Fig. 2. Formation of benzoic and cinnamic acids during the oxidation of phenylpropionic acid $(25 \mu \mathrm{mole} / \mathrm{ml}$.) by Nocardia opaca.

A similar experiment was terminated after $48 \mathrm{hr}$. (i.e. at the half-way stage). The contents of the flask were centrifuged and extracted as described under Methods. Paper chromatography of the extract showed the presence of an unsaturated acid substance with an $R_{F}$ value identical with that of authentic cinnamic acid. Benzoic acid was indicated similarly with the bromophenol blue-methyl red spray.

Phenylvaleric and phenylheptylic acid were also shown by absorptiometric methods to be converted to benzoic acid with formation of cinnamic acid as an intermediate (Table 2). Benzoic acid was formed at a linear rate from phenylpropionic acid (Fig. 2), but there is an increasing lag in its formation as the fatty acid chain lengthens. This observation is in agreement with the supposition that the chain length is reduced stepwise by $\beta$-oxidation. 
Table 2. Concentrations of cinnamic and benzoic acids at intervals during the metabolism of phenylvaleric and phenylheptylic acids by Nocardia opaca

Culture flasks contained $100 \mathrm{ml} .0 \cdot 0133 \mathrm{~m}$-phosphate $(\mathrm{pH} 7 \cdot 2) 10 \mu$ mole $/ \mathrm{ml}$. phenylvaleric or phenylheptylic acids, and $250 \mathrm{mg}$. (dry weight) cells of $\mathbf{N}$. opaca. $5 \mathrm{ml}$. samples were withdrawn aseptically at stated intervals.

\begin{tabular}{|c|c|c|c|c|}
\hline \multirow{5}{*}{$\begin{array}{c}\text { Time (hr.) } \\
0\end{array}$} & \multicolumn{4}{|c|}{ Acids present initially } \\
\hline & \multicolumn{2}{|c|}{ Phenylvaleric } & \multicolumn{2}{|c|}{ Phenylheptylic } \\
\hline & \multicolumn{4}{|c|}{ Acids found $(\mu \mathrm{mole} / \mathrm{ml})}$. \\
\hline & Cinnamic & Benzoic & Cinnamic & Benzoic \\
\hline & o & 0 & 0 & 0 \\
\hline 24 & $1 \cdot 73$ & $1 \cdot 09$ & 0.97 & $0 \cdot 29$ \\
\hline 48 & $4 \cdot 07$ & $3 \cdot 53$ & $2 \cdot 47$ & $1 \cdot 45$ \\
\hline 72 & $2 \cdot 13$ & $8 \cdot 15$ & $4 \cdot 38$ & 3.79 \\
\hline 96 & $\mathbf{0}$ & $10 \cdot 65$ & $1 \cdot 60$ & $7 \cdot 55$ \\
\hline 144 & $\mathbf{0}$ & $10 \cdot 70$ & 0 & $10 \cdot 20$ \\
\hline
\end{tabular}

Phenylundecanoic acid was toxic in manometric experiments at concentrations exceeding 0.001-M. It increased the oxygen uptake at this concentration (Table 3). For comparison phenylcaprylic acid and phenylpropionic acid were included. The experiment was continued overnight, and the following morning the contents of the vessels were centrifuged and examined spectrochemically. Phenylpropionic acid had been converted to benzoic acid but no trace of the latter could be found in the experiment with undecanoate. Thus the breakdown of phenylundecanoic acid differs from that of the other odd-numbered phenyl substituted fatty acids used. This is of interest in view of the work of Mahler (1953) with animal systems where the enzyme that activates $C_{4}-C_{10}$ fatty acids caused a slow activation of the $\mathrm{C}_{11}$ and did not activate the $\mathrm{C}_{12}$ acid at all.

Table 3. The oxygen uptake of Nocardia opaca in the presence of phenylpropionic, phenylcaprylic and phenylundecanoic acids

Each vessel contains $20 \mathrm{mg}$. dry weight of a washed suspension of glucose-grown cells of N. opaca, $0.5 \mathrm{ml}$. 0.06 M-phosphate $(\mathrm{pH} \mathrm{7.2)}$ and distilled water to give $2.25 \mathrm{ml}$. After overnight incubation $0.25 \mathrm{ml}$. of distilled water or $0.01 \mathrm{M}$-sodium salts of the acids were tipped in from the side arms.

\begin{tabular}{cc} 
Addition & $\mathrm{O}_{2}$ uptake in $180 \mathrm{~min}$. \\
None & $(\mu \mathrm{l})$. \\
Phenylpropionate & 63 \\
Phenylcaprylate & $\mathbf{7 8 \cdot 8}$ \\
Phenylundecanoate & $\mathbf{1 7 7 \cdot 6}$ \\
\multicolumn{2}{c}{$\mathbf{1 2 7 \cdot 7}$} \\
Experiments with phenylacetate and even-numbered phenyl-substituted \\
\multicolumn{2}{c}{ fatty acids }
\end{tabular}

In contrast to its behaviour with benzoic acid and the odd-numbered phenylsubstituted fatty acids Nocardia opaca grew well on phenylacetic acid (PhC-2), phenylbutyric acid (PhC-4) and phenylcaproic acid (PhC-6). There was a time 
lag before growth commenced on $\mathrm{PhC}-4$ and $\mathrm{PhC}-6$, this being longer with the latter (Table 4). Phenylcaprylic acid (PhC-8) did not support growth at concentrations greater than 0.001-M.

\section{Table 4. Growth of Nocardia opaca on phenyl-substituted fatty acids}

Growth in mineral salts with $0.01 \mathrm{M}$-sodium salts of the acids as substrates. Incubated at $25^{\circ}$ and examined periodically. $0=$ no growth; $(+)=$ very slight growth; $+=$ definite growth; +++ to $+++++=$ good growth.

\begin{tabular}{lcccc}
\multicolumn{1}{c}{ Substrate } & $\mathbf{3}$ & $\mathbf{1 3}$ & 23 & 36 \\
Benzoate & $\mathbf{0}$ & $\mathbf{0}$ & $\mathbf{0}$ & $\mathbf{0}$ \\
Cinnamate & $\mathbf{0}$ & $\mathbf{0}$ & $(+)$ & $(+)$ \\
Phenylacetate & +++ & ++++ & +++++ & ++++++ \\
Phenylpropionate & $\mathbf{0}$ & $\mathbf{0}$ & $(+)$ & $(+)$ \\
Phenylbutyrate & + & +++ & ++++ & +++++ \\
Phenylvalerate & 0 & $(+)$ & $(+)$ & $(+)$ \\
Phenylcaproate & 0 & + & +++++ & +++++ \\
Phenylheptylate & 0 & 0 & 0 & $(+)$
\end{tabular}

In manometric experiments glucose-grown cells gave increased oxygen uptake in the presence of phenylacetate, phenylbutyrate, phenylcaproate (Table 5), and phenylcaprylate (Table 3). Also an adaptive curve was obtained with phenylacetate but not with phenylbutyrate (Fig. $3(a)$ ). The other phenyl substituted acids behaved similarly to phenylbutyrate. Oxidation of phenylacetate by glucose-grown cells occurred without a lag if they were first incubated with PhC-4, PhC-6 or PhC-8 (Fig. $3 b$ ), but the odd-numbered members $\mathrm{PhC}-3$, PhC-5, PhC-7 were ineffective. This supports the view that the oxidation of phenylbutyrate, phenylcaproate and phenylcaprylate proceeds via phenylacetate as would be expected for $\beta$-oxidation.

Attempts to detect phenylacetic acid during the metabolism of the evennumbered phenyl substituted acids were not successful. However, evidence was obtained of the production of a phenolic compound ( $o$-hydroxyphenylacetic acid) common to the metabolism of phenylacetic, phenylbutyric, phenylcaproic and phenylcaprylic acids.

\section{The production of o-hydroxyphenylacetic acid from phenylacetate, phenyl- butyrate, phenylcaproate and phenylcaprylate by washed cells of \\ Nocardia opaca}

Culture flasks containing either $20 \mu \mathrm{mole} / \mathrm{ml}$. phenylacetate, phenylbutyrate, $10 \mu \mathrm{mole} / \mathrm{ml}$. phenylcaproate, or $5 \mu \mathrm{mole} / \mathrm{ml}$. phenylcaprylate and $339 \mathrm{mg}$. (dry weight) of glucose-grown cells were set up as described under Methods.

The experiment with $\mathrm{PhC}-2, \mathrm{PhC}-4, \mathrm{PhC}-6$ was concluded after 7 days but that with PhC-8 continued for 12 days. After centrifuging, a sample (2 ml.) was taken for spectrochemical analysis and the remainder acidified and extracted with ether as previously described. Paper chromatography of the extracts showed that phenols were present in all cases and pure specimens were obtained by ether extraction of the spots from six papers in a Soxhlet 
apparatus. It was necessary to spray the papers with $\mathrm{N}$-hydrochloric acid before extraction. The main phenolic product in all cases was $o$-hydroxyphenylacetic acid. It had the same $R_{F}$ value and the spots were identical with an
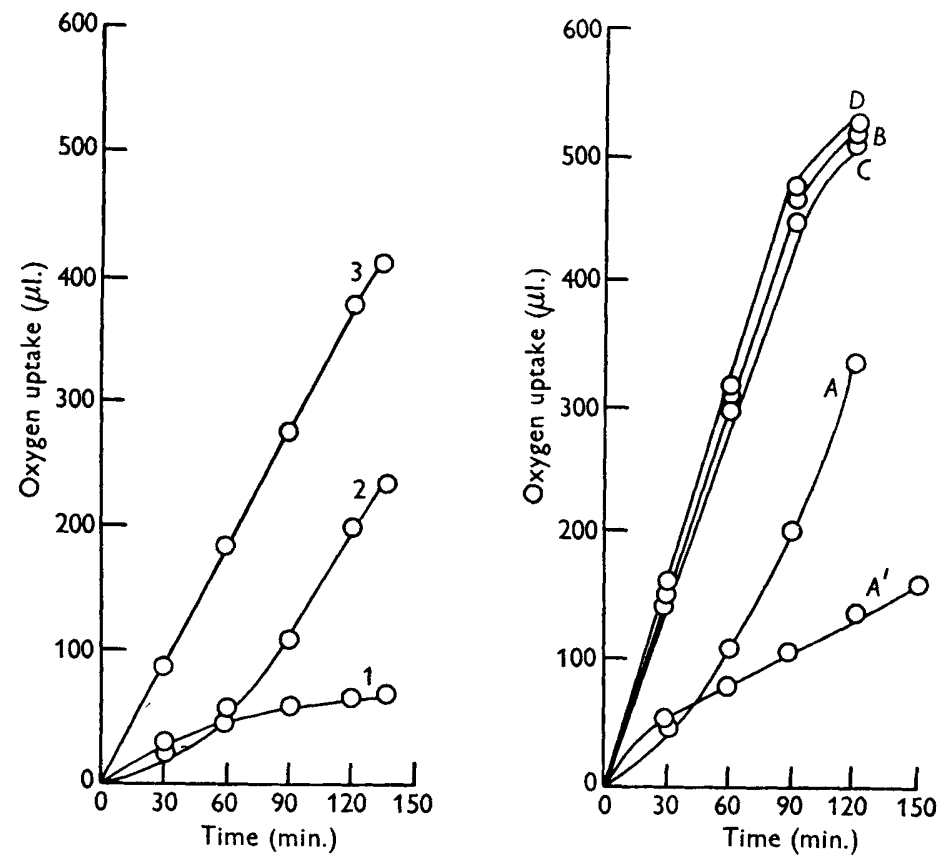

Fig. 3. (a) Adaptive patterns of glucose-grown cells of Nocardia opaca with the following compounds: 1 , no substrate; 2 , phenylacetate; 3 , phenylbutyrate. Each vessel contained $20 \mathrm{mg}$. dry weight of cells and $2 \mu \mathrm{mole} / \mathrm{ml}$. of the respective substrate. (b) Effect on phenylacetate oxidation of exposure of glucose-grown cells to distilled water (A and $\left.A^{\prime}\right)$, phenylbutyrate $(0.4 \mu \mathrm{mole} / \mathrm{ml}$.) (B), phenylcaproate $(0.4 \mu \mathrm{mole} / \mathrm{ml}$.) (C), and phenylcaprylate $(0 \cdot 4 \mu \mathrm{mole} / \mathrm{ml}$.) (D). Phenylacetate $(2 \mu \mathrm{mole} / \mathrm{ml}$.) added subsequently to $\mathbf{A}, \mathbf{B}, \mathbf{C}$ and $\mathbf{D}$. Distilled water added to $\mathbf{A}^{\prime}$.

authentic sample in three different developing solvents: $n$-butanol + acetic acid + water $(4: 5: 5)$, $n$-butanol + pyridine + saturated aqueous sodium chloride solution +ammonia sp.gr. 0.880 (4: $8: 5: 3$ ) (Bray, Lake, Thorpe \& White, 1950), and the buffered ammonia + ammonium carbonate solvent of Fewster

Table 5. The oxygen uptake of Nocardia opaca in the presence of phenylacetic, phenylbutyric and phenylcaproic acids

Each vessel contained $5.7 \mathrm{mg}$. dry weight of glucose-grown cells of $N$. opaca, $0.5 \mathrm{ml}$. of $0.66 \mathrm{~m}$-phosphate $(\mathrm{pH} \mathrm{7.2)}$ and distilled water to give $2.0 \mathrm{ml}$. After overnight incubation a further $0.5 \mathrm{ml}$. of distilled water or $0.01 \mathrm{M}$-solutions of the sodium salts of the acids were tipped in from the side arm.

\begin{tabular}{lc}
\multicolumn{1}{c}{ Addition } & $\mathrm{O}_{2}$ uptake in $180 \mathrm{~min}$. \\
None & $(\mu \mathrm{l})$. \\
Phenylacetate & 119 \\
Phenylbutyrate & 194 \\
Phenylcaproate & 241 \\
& 330
\end{tabular}


$\&$ Hall (1951). The $R_{F}$ values were $0 \cdot 95,0.74$ and $0 \cdot 48$ respectively. $o$-Hydroxyphenylacetic acid was well separated from the para isomer. The main spot given by the extracted material showed both phenolic and acidic properties when sprayed with the appropriate reagents. o-Hydroxyphenylacetic acid was the only phenolic product obtained from phenylacetic and phenylcaprylic acids but a second phenolic acid $\left(\boldsymbol{R}_{F} \mathbf{0} \cdot 40\right.$ in buffered ammonia + ammonium carbonate solvent) was present in the extracts from the phenylbutyrate and phenylcaproate cultures.

Examination of the ultraviolet absorption spectra of the centrifuged media at the conclusion of the experiment showed that approximately $3 \%$ of phenylacetate, $12 \%$ of phenylbutyrate, $14 \%$ of phenylcaproate and $7 \%$ of phenylcaprylate had been converted to phenolic substances. No trace of benzoic or cinnamic acids could be detected. The production of a common product (o-hydroxyphenylacetic acid) from the even-numbered phenyl-substituted fatty acids confirms that their oxidation proceeds via phenylacetate as indicated by the adaptation experiments.

Since the presence of phenylacetate as impurity in the above acids would invalidate this conclusion samples were examined by paper chromatography. One spot only was obtained from each acid and these were very clearly distinguished from phenylacetic acid (by their $R_{F}$ values). Phenylcapric and phenyllauric acids gave two spots on the paper chromatogram and were not included in the present work. These acids melted over a range of $1^{\circ}$ and $2^{\circ}$ respectively showing that in this case the paper chromatographic methods were more sensitive to impurities than melting point determinations.

\section{DISCUSSION}

It is well established that the enzyme systems involved in the oxidation of the normal fatty acids are the same for the oxidation of the phenyl-substituted fatty acids (Rittenberg \& Ivler, 1952; Mahler, 1953).

The production of benzoic acid from odd-numbered phenyl-substituted fatty acids (PhC-3, PhC-5, PhC-7) and o-hydroxyphenylacetic acid from evennumbered phenyl substituted fatty acids (PhC-4, PhC-6, PhC-8) supports the view that the mechanism of breakdown of fatty acids by Nocardia opaca takes place by $\beta$-oxidation (cf. Knoop's classical work (Breusch, 1948)). The detection of cinnamic acid from $\mathrm{PhC}-3, \mathrm{PhC}-5, \mathrm{PhC}-7$ is in line with this hypothesis. Although benzoic acid is formed almost quantitatively from the odd-numbered phenyl-substituted fatty acids (Table 2), the yields of $o$-hydroxyphenylacetic acid from even-numbered acids are relatively low $(<15 \%)$. This phenol appears to arise from a side reaction in the main metabolic pathway of phenylacetic acid. It is not attacked by $N$. opaca and therefore accumulates in the medium. The remainder of the phenylacetate is rapidly consumed and the metabolic pathway by which this is achieved is under investigation.

The production of $o$-hydroxyphenylacetic acid from phenylacetate by Nocardia opaca is of interest in the light of its occurrence during penicillin formation (Pan, 1955). 
The work of Silliker \& Rittenberg (1952) with Serratia marcescens using the technique of simultaneous adaption suggests that $\beta$-oxidation does not occur in this organism. Our strain of Nocardia opaca differs from the strain of Serratia marcescens used by these workers in that the oxidation of fatty acids by the latter organism is catalysed by adaptive enzymes. No adaptive mechanism was observed with Nocardia opaca. Further, cells of Serratia marcescens which can oxidize higher fatty acids do not oxidize propionic, butyric or valeric acids due to 'impermeability of the living cells to these acids' (Silliker \& Rittenberg, 1951). In view of these major differences, and because in Nocardia opaca we are dealing with an acid-fast organism with a pronounced lipid metabolism it is not surprising that its mode of attack on fatty acids differs from that found in organisms not normally regarded as fat decomposers.

We are indebted to Dr S. C. Rittenberg for his kindness in supplying us with samples of $\omega$-phenyl-substituted fatty acids and Dr S. W. Stroud for the gift of some pure $o$-hydroxyphenylacetic acid.

\section{REFERENCES}

Bray, H. G, Lake, H. J., Thorpe, W. V. \& White, K. (1950). Further observations on the use of paper chromatography for the detection of phenolic compounds in metabolic studies. Biochem. J. 47, xiii.

Breusch, F. L. (1948). The biochemistry of fatty acid catabolism. Advanc. Enzymol. 8, 343.

Evans, R. A., PARR, W. H. \& Evans, W. C. (1949). Paper partition chromatography of phenolic substances. Nature, Lond. 164, 674.

Fewster, M. E. \& Hall, D. A. (1951). Application of buffered solvent systems to the detection of aromatic acids by paper partition chromatography. Nature, Lond. 168, 78.

Mahler, H. R. (1953). Role of coenzyme A in fatty acid metabolism. Fed. Proc. $12,694$.

PAN, S. C. (1955). Colorimetric determination of $o$-hydroxyphenylacetic acid in samples from penicillin fermentations. Analyt. Chem. 27, 65.

Rittenberg, S. C. \& Ivler, D. (1952). Oxidation of phenyl-substituted fatty acids by bacteria. Bact. Proc. p. 140.

Silliker, J. H. \& Rittenberg, S. C. (1951). Studies on the aerobic oxidation of fatty acids by bacteria. II. Application of the technique of simultaneous adaption to the study of the mechanism of fatty acid oxidation in Serratia marcescens. J. Bact. 61, 661.

Silliker, J. H. \& Rittenberg, S. C. (1952). Studies in the aerobic oxidation of fatty acids by bacteria. III. The effect of $2: 4$ dinitrophenol on the oxidation of fatty acids by Serratia marcescens. J. Bact. 64, 197.

Webley, D. M. (1954). The morphology of Nocardia opaca Waksman \& Henrici (Proactinomyces opacus Jensen) when grown on hydrocarbons, vegetable oils, fatty acids and related substances. J. gen. Microbiol. 11, 420.

Webley, D. M. \& DE Kock, P. C. (1952). The metabolism of some saturated aliphatic hydrocarbons, alcohols and fatty acids by Proactinomyces opacus Jensen (Nocardia opaca Waksman \& Henrici). Biochem. J. 51, 371.

Webley, D. M. \& DufF, R. B. (1955). A convenient shaking machine for growing micro-organisms. J. appl. Bact. 18, 122. 